Daniel B. Costa, Beth Israel Deaconess Medical Center, Harvard Medical School Alice T. Shaw, Massachusetts General Hospital, Harvard Medical School, Boston, MA; Sai-Hong I. Ou, Chao Family Comprehensive Cancer Center, University of California Invine School of Medicine, Invine; S. Martin Shreeve, Paulina Selaru, and Keith D. Wilner, Pfizer Oncology, La Jolla, CA; Benjamin J. Solomon, Peter MacCallum Cancer Centre, Melbourne, Victoria, Australia; Gregory J. Riely, Memorial SloanKettering Cancer Center; Patrick Schnell, Pfizer Oncology, New York, NY; Myung-Ju Ahn, Sungkyunkwan University School of Medicine, Samsung Medical Center, Seoul, Korea; Caicun Zhou, Shanghai Pulmonary Hospital, Shanghai, People's Republic of China; Anna Polli, Pfizer Oncology, Milan; Lucio Crinò, Perugia University Medical School, Perugia, Italy; Robin Wiltshire, Pfizer Oncology, Tadworth, United Kingdom; and D. Ross Camidge, University of Colorado Denver, Aurora, CO.

Published online ahead of print at www.jco.org on January 26, 2015.

Processed as a Rapid Communication manuscript.

Support information appears at the end of this article.

Terms in blue are defined in the glossary, found at the end of this article and online at www.jco.org.

Authors' disclosures of potential conflicts of interest are found in the article online at www.jco.org. Author contributions are found at the end of this article.

Clinical trial information: NCT00932451, NCT00932893.

Corresponding author: Daniel B. Costa, $\mathrm{MD}, \mathrm{PhD}$, Division of Hematology/Oncology, Beth Israel Deaconess Medical Center, 330 Brookline Ave, Boston, MA 02215; e-mail: dbcosta@bidmc.harvard.edu. () 2015 by American Society of Clinica Oncology

0732-183X/15/3317w-1881w/\$20.00

DOI: $10.1200 / J C O .2014 .59 .0539$

\title{
Clinical Experience With Crizotinib in Patients With Advanced ALK-Rearranged Non-Small-Cell Lung Cancer and Brain Metastases
}

Daniel B. Costa, Alice T. Shaw, Sai-Hong I. Ou, Benjamin J. Solomon, Gregory J. Riely, Myung-Ju Ahn, Caicun Zhou, S. Martin Shreeve, Paulina Selaru, Anna Polli, Patrick Schnell, Keith D. Wilner, Robin Wiltshire, D. Ross Camidge, and Lucio Crinò

Listen to the podcast by Dr Rosell at www.jco.org/podcasts

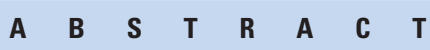

\section{Purpose}

Crizotinib is an oral kinase inhibitor approved for the treatment of $A L K$-rearranged non-small-cell lung cancer (NSCLC). The clinical benefits of crizotinib in patients with brain metastases have not been previously studied.

\section{Patients and Methods}

Patients with advanced ALK-rearranged NSCLC enrolled onto clinical trial PROFILE 1005 or 1007 (randomly assigned to crizotinib) were included in this retrospective analysis. Patients with asymptomatic brain metastases (nontarget or target lesions) were allowed to enroll. Tumor assessments were evaluated every 6 weeks using RECIST (version 1.1).

\section{Results}

At baseline, $31 \%$ of patients (275 of 888) had asymptomatic brain metastases; 109 had received no prior and 166 had received prior brain radiotherapy as treatment. Among patients with previously untreated asymptomatic brain metastases, the systemic disease control rate (DCR) at 12 weeks was $63 \%(95 \% \mathrm{Cl}, 54 \%$ to $72 \%)$, the intracranial DCR was $56 \%(95 \% \mathrm{Cl}$, $46 \%$ to $66 \%$ ), and the median intracranial time to progression (TTP) was 7 months $(95 \% \mathrm{Cl}$, 6.7 to 16.4). Among patients with previously treated brain metastases, the systemic DCR was $65 \%(95 \% \mathrm{Cl}, 57 \%$ to $72 \%)$, the intracranial DCR was $62 \%(95 \% \mathrm{Cl}, 54 \%$ to $70 \%)$, and the median intracranial TTP was 13.2 months ( $95 \% \mathrm{Cl}, 9.9$ to not reached). Patients with systemic disease control were also likely to experience intracranial disease control at 12 weeks (correlation coefficient, $0.7652 ; P<.001$ ). Among patients without baseline brain metastases who developed progressive disease $(n=253)$ after initiation of crizotinib, $20 \%$ were diagnosed with brain metastases.

\section{Conclusion}

Crizotinib was associated with systemic and intracranial disease control in patients with $A L K$ rearranged NSCLC who were ALK inhibitor naive and had brain metastases. However, progression of preexisting or development of new intracranial lesions while receiving therapy was a common manifestation of acquired resistance to crizotinib.

\section{J Clin Oncol 33:1881-1888. (C) 2015 by American Society of Clinical Oncology}

\section{INTRODUCTION}

Lung cancer is_-and has been for the last several decades - the leading cause of cancer-related mortality for both men and women worldwide. ${ }^{1}$ The last decade has revealed the heterogeneity of molecular abnormalities present within non-small-cell lung cancer (NSCLC) and led to the development of tyrosine kinase inhibitors (TKIs), in what is now commonly referred to as precision oncology. ${ }^{2,3} \mathrm{Re}-$ arrangements, either inversions or translocations, characterize the genomic changes involving anaplastic lymphoma kinase (ALK) that are observed in NSCLC. ${ }^{4,5}$ Inversions in the short arm of chromosome 2 that juxtapose echinoderm microtubuleassociated protein-like 4 (EML4) with $A L K$ and produce $E M L 4-A L K$-fusion tyrosine kinases ${ }^{4,6}$ are the most common changes noted. The reported prevalence of $A L K$ rearrangements in unselected NSCLC is approximately 5\%. ${ }^{7-12}$ Tumors with ALK rearrangements are addicted to ALK signaling and are inhibited by ALK TKIs in preclinical models., ${ }^{93-15}$ 
Crizotinib - a multitargeted TKI with activity against MET, ALK, ${ }^{13-15}$ and ROS1 ${ }^{16,17}$ — was approved by the US Food and Drug Administration in August 2011 for advanced NSCLC positive for ALK rearrangements. ${ }^{5,18-20}$ More recently, the randomized phase III PROFILE 1007 trial showed that for previously treated patients with $A L K$-rearranged NSCLC, crizotinib led to improved outcomes (progression-free survival [PFS; primary outcome], objective response rate $[\mathrm{ORR}]$, and quality-of-life measurements) when compared with docetaxel or pemetrexed. ${ }^{21}$ The median overall survival (OS) of patients with $A L K$-rearranged NSCLC from the phase I and II trials (PROFILE 1001 and 1005, respectively) was reported as an unprecedented 29.6 months for 120 patients who continued crizotinib even beyond disease progression (PD). ${ }^{22}$

Despite the significant clinical experience with crizotinib in controlling systemic sites of tumor burden in patients with ALKrearranged NSCLC, few reports of any depth have studied whether this ALK inhibitor controls brain metastases in ALK TKI-naive NSCLC. The CNS is a common site of disease in advanced NSCLC, and patients with CNS metastases are under-represented in clinical trials of systemic therapies. ${ }^{18,23,24}$ As systemic therapies with TKIs continue to improve the duration of disease control for patients with oncogene-driven NSCLCs, the control and prevention of brain metastases have emerged as important therapeutic issues. ${ }^{24}$ Most systemic cytotoxic chemotherapies and some TKIs seem to inefficiently cross the intact blood-brain barrier. ${ }^{25-27}$ Here, we present a pooled retrospective analysis of crizotinib in patients with $A L K$-rearranged NSCLC and concurrent brain metastases from the clinical trials PROFILE 1005 and 1007, with the goal of understanding how this TKI affects the control of brain metastases.

\section{PATIENTS AND METHODS}

\section{Patients and Treatment}

Patients with $A L K$-rearranged advanced NSCLC enrolled onto PROFILE 1005 or 1007 (randomly assigned to crizotinib) were included in this analysis. These studies are registered with ClinicalTrials.gov as NCT00932451 and NCT00932893, respectively. ALK rearrangement was detected by breakapart fluorescent in situ hybridization. ${ }^{18}$ Eligibility criteria for both studies have been described previously ${ }^{21}$ and were similar. Disease was required to be measurable per RECIST (version 1.1) ${ }^{28}$ for PROFILE 1007. Patients with asymptomatic brain metastases, either treated or untreated at baseline, were eligible for both studies. All patients provided written informed consent, and all patients included in this analysis received crizotinib at a starting dose of 250 mg orally twice per day, with appropriate dosing modification as needed. Data cutoff for this analysis was February 15, 2012, for patients in PROFILE 1005 and March 30, 2012, for those in PROFILE 1007. Our study was a retrospective exploratory analysis of PROFILE 1005 and 1007.

\section{Measurements of Systemic Disease and Brain Sites of Disease}

Tumor assessments were performed every 6 weeks from the date of first dose (PROFILE 1005) or the date of random assignment (PROFILE 1007), and all analyses were based on investigator assessment using RECIST (version 1.1). Baseline brain imaging was required in both studies, and if brain metastases were detected (investigators used either computed tomography only $[\mathrm{n}=134]$, magnetic resonance imaging only $[\mathrm{n}=138]$, or both modalities $[\mathrm{n}=1]$ for patients with detected brain metastases; for two patients, neither method of imaging was recorded), subsequent brain imaging was required at 6-week intervals. Otherwise, imaging to assess brain metastases on treatment was performed as clinically indicated. Systemic lesions and brain metastases were monitored as target or nontarget lesions.

\section{Statistical Analyses}

Because a majority of baseline brain metastases in these two studies were identified as nontarget lesions, disease control rate (DCR) at 12 weeks (to allow at least two imaging reassessments) was determined to be the best clinical correlate of intracranial benefit using RECIST (version 1.1) for this retrospective analysis. DCR (systemic [ie, all sites outside brain] or intracranial) was defined as the percentage of patients with complete response (CR), partial response $(\mathrm{PR})$, or stable disease. Both intracranial and systemic DCRs were evaluated at 12 weeks after the start of treatment or random assignment. Best overall objective response for measurable intracranial lesions was also determined. A confirmatory imaging assessment was required to confirm CR or PR. Systemic time to progression (TTP) was defined as the time from the first dose (PROFILE 1005) or from random assignment (PROFILE 1007) to the first documentation of objective systemic tumor progression. Intracranial TTP was defined as the time from the first dose (PROFILE 1005) or from random assignment (PROFILE 1007) to the first documentation of intracranial tumor progression.

PFS, TTP, and OS were analyzed using the Kaplan-Meier method. The median event time and the corresponding two-sided 95\% CI (BrookmeyerCrowley method) were provided. Systemic and intracranial DCRs at 12 weeks were analyzed for degree of association using Pearson's $\chi^{2}$ test, and the $\phi$ coefficient was provided. Differences between baseline clinicopathologic characteristics of the groups were assessed using Pearson's $\chi^{2}$ or Fisher's exact test and indicated accordingly. All analyses were performed with SAS statistical software (version 9.2; SAS Institute, Cary, NC). Additional details can be found in the Appendix (online only).

\section{RESULTS}

\section{Baseline Characteristics of Patients}

Baseline clinicopathologic characteristics of the 888 patients pooled from PROFILE 1005 and 1007 are listed in Table 1. Three groups within this pooled population were defined (Fig 1): one, patients with untreated (no prior radiotherapy) asymptomatic brain metastases (12\%); two, patients with previously treated (with intracranial radiotherapy at any time during cancer course) asymptomatic brain metastases (19\%); and three, patients with no detectable brain metastases at baseline (69\%). The three groups were similar with regard to most baseline characteristics, except age and ethnicity (more Asians in untreated brain metastases group, which may reflect local clinical practices in management of CNS disease rather than tumor biology) and the duration of crizotinib treatment (median, 24.7 [range, 0.1 to 81.7 ], 22.0 [1.4 to 102.4], and 29.3 weeks [0.3 to 108.3], respectively). Treatment-emergent adverse events were similar for patients with or without baseline brain metastases while receiving crizotinib (data not shown).

\section{Disease Control With Crizotinib}

All 888 patients included in the analysis were evaluable for systemic response (Table 2). In the patients with untreated brain metastases, the systemic DCR at 12 weeks was 63\% (95\% CI, 54\% to $72 \%$ ). These same patients had an intracranial DCR of $56 \%$ (95\% CI, $46 \%$ to $66 \%$ ) at 12 weeks. Systemic ORR in this group of patients was $53 \%$ (95\% CI, $43 \%$ to $63 \%)$. The intracranial ORR, which only accounts for confirmed CRs and PRs of target CNS lesions, was $18 \%$ (95\% CI, 5\% to $40 \%)$ in the group with target baseline lesions (Table 2).

In patients with previously treated brain metastases, the systemic DCR at 12 weeks was $65 \%$ (95\% CI, 57\% to $72 \%)$. These patients had an intracranial DCR of $62 \%$ (95\% CI, $54 \%$ to $70 \%)$ at 12 weeks. 


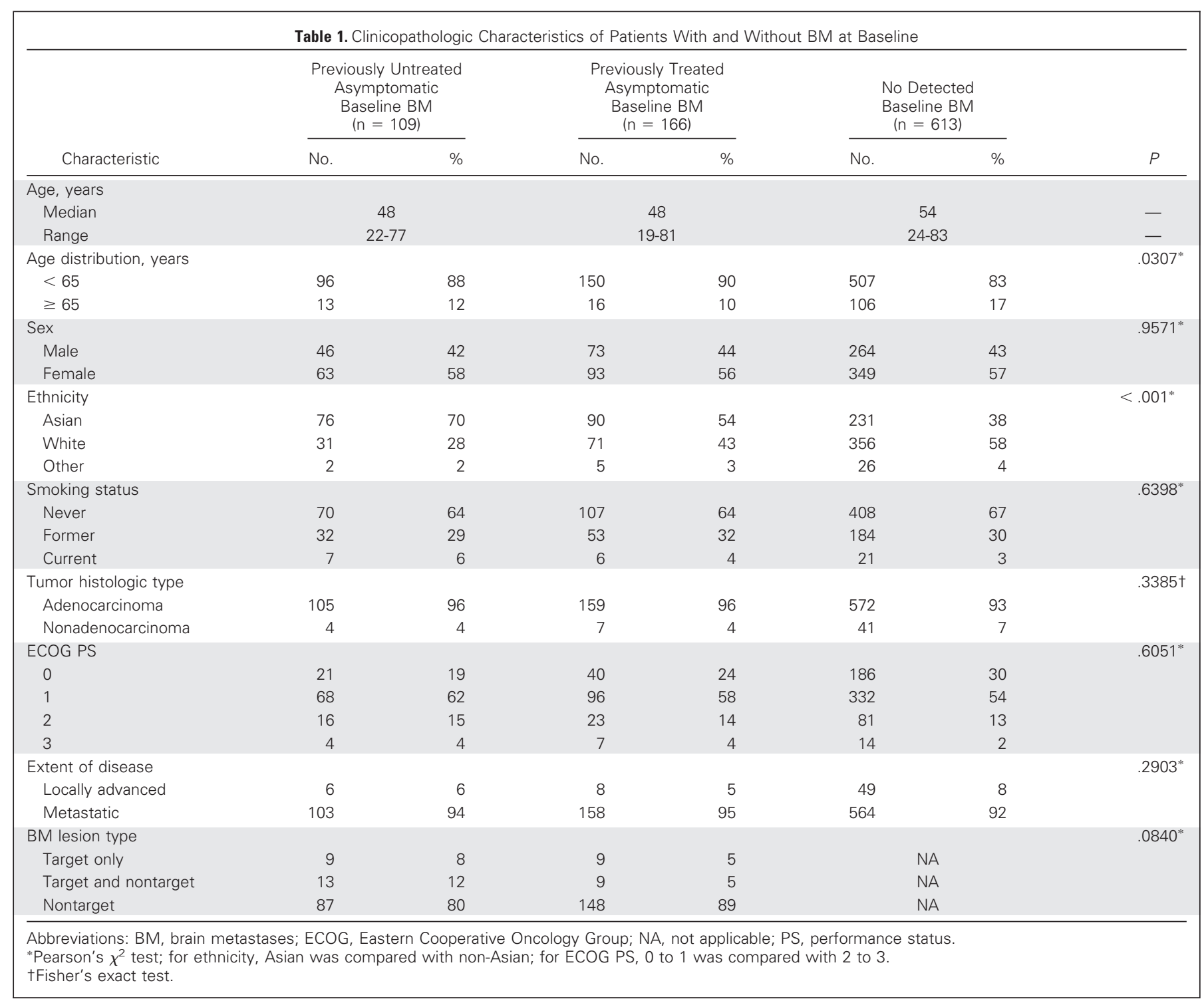

Systemic and intracranial (within aforementioned limitations) ORRs in this group were $46 \%$ (95\% CI, 39\% to 54\%) and 33\% (95\% CI, 13\% to $59 \%$ ), respectively, in the group with target lesions.

When systemic DCR at 12 weeks was evaluated in conjunction with intracranial DCR at 12 weeks, a positive and statistically significant relationship was found (correlation coefficient, $0.7652 ; P<.001$ ) in the pooled group of patients with previously treated or untreated brain metastases, suggesting that patients with systemic DCR at 12 weeks were also likely to experience intracranial DCR at 12 weeks and vice versa.

In patients with target CNS lesions with previously untreated (Fig 2A) and treated (Fig 2B) brain metastases, target lesion tumor regression was observed even when not confirmed as an objective response. This observation was noted in the majority of patient cases. In patients with no detectable brain metastases at baseline, the systemic DCR at 12 weeks was 71\% (438 of 613), and the systemic ORR was 55\% (336 of 613 ).

\section{Disease Control and Sites of PD With Crizotinib}

Overall and median PFS for patients with or without brain metastases from the initiation of crizotinib treatment are depicted in Figure 3A and Table 2, respectively. The systemic PFS (Table 2; Fig 3B) was similar for patients with or without brain metastases before initiation of crizotinib.

For patients with untreated brain metastases, the median intracranial TTP was 7 months (95\% CI, 6.7 to 16.4), and the median systemic TTP was 12.5 months (95\% CI, 7.0 to 14.0), as shown in Figure $4 \mathrm{~A}$ and Table 2. Progression during crizotinib treatment occurred in $43 \%$ of patients (47 of 109) in this group at the time of data cutoff. Of the patients with nontarget or new lesions as PD, the CNS was the most common site of progression, occurring in $70 \%$ of patients (30 of 43).

For patients with previously treated brain metastases, the median intracranial TTP was 13.2 months (95\% CI, 9.9 to not reached), and the systemic median TTP was 14 months (95\% CI, 13.5 to 18.0$)$, as 


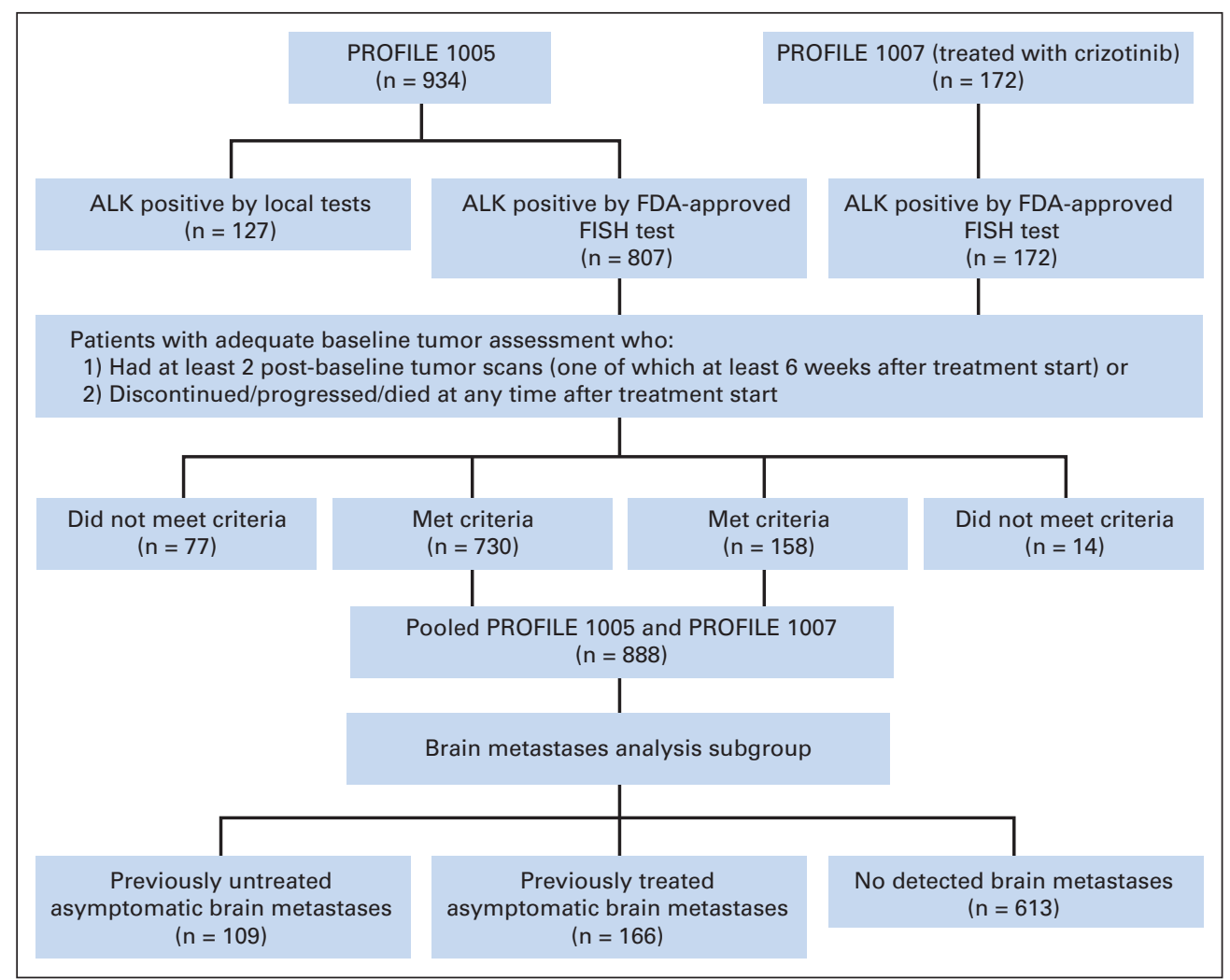

Fig 1. CONSORT diagram. ALK, anaplastic lymphoma kinase; FDA, US Food and Drug Administration; FISH, fluorescent in situ hybridization.

shown in Figure $4 \mathrm{~B}$ and Table 2. Progression while receiving crizotinib occurred in $37 \%$ of patients ( 62 of 166) at the time of data cutoff. Of the patients with nontarget or new lesions as $\mathrm{PD}$, the CNS was the most common site of progression, occurring in $72 \%$ of patients (39 of 54).

For patients without evidence of brain metastases at initiation of crizotinib treatment, the median overall TTP was 9.8 months $(95 \%$ CI, 8.4 to 11.7). The development of brain metastases (by investigator review of imaging scans) occurred in $20 \%$ of patients (51 of 253) with $\mathrm{PD}$ at the time of data cutoff. The median time to detection of brain metastases in these 51 patients was 29.9 weeks (range, 2.6 to 79 weeks).

In all patients, including those with progressive brain metastases, continued use of crizotinib was allowed if the treating physician believed the patient continued to derive clinical benefit. Data from 34 patients with new brain metastases (from group without initially detected brain metastases) in whom this approach was undertaken were evaluated. In this group of patients, the post-PD median treatment duration was 19.3 weeks (range, 3.1 to 63.6 weeks). Of these, most (27 of 34) received local CNS treatment (with whole-brain radiotherapy or stereotatic radiotherapy) followed by continued crizotinib, whereas seven patients continued crizotinib beyond $\mathrm{PD}$ and did not receive radiotherapy.

\section{OS During Crizotinib Treatment}

OS was immature by the data cutoff date for this analysis, with only $29 \%, 34 \%$, and $27 \%$ of patients known to have died in the groups with untreated brain metastases, previously treated brain metastases, and no detectable brain metastases at baseline, respectively. Preliminary estimates for the 6-month survival probabilities were $77 \%$ (95\% CI, $67 \%$ to $85 \%$ ), $74 \%$ (95\% CI, $66 \%$ to $80 \%$ ), and
$85 \%$ (95\% CI, $81 \%$ to $87 \%$ ) for the three groups with untreated, previously treated, and no brain metastases, respectively; preliminary estimates for the 1-year survival probabilities were 59\% (95\% CI, $45 \%$ to $70 \%$ ), $64 \%$ (95\% CI, $55 \%$ to $71 \%$ ), and $69 \%$ (95\% CI, $64 \%$ to $73 \%$ ) for these three groups, respectively.

\section{DISCUSSION}

Crizotinib is a multitargeted TKI with proven efficacy against $A L K$ rearranged tumors and is approved in several countries for the treatment of $A L K$-rearranged advanced NSCLC. ${ }^{18,29}$ Approximately one third of patients with advanced $A L K$-rearranged NSCLC after failure of at least one prior systemic therapy, as described here, have brain metastases at baseline. The penetration of crizotinib into the CNS and measurements of CSF concentrations of the drug have not been fully investigated. Most small-molecule TKIs-including $\mathrm{cr}$ izotinib, ${ }^{30}$ imatinib, ${ }^{25}$ erlotinib, ${ }^{26}$ and gefitinib ${ }^{27}$ - have been shown to have low CSF-to-plasma ratios. However, it was unclear before our analysis whether crizotinib had activity in the management of brain metastases.

To our knowledge, our retrospective analysis of crizotinibtreated patients with $A L K$-rearranged NSCLC and asymptomatic treated or untreated brain metastases pooled from PROFILE 1005 and 1007 represents the largest data set on brain metastases in $A L K$ rearranged NSCLC analyzed to date. It demonstrated a high degree of concordance between initial disease control of brain metastases and systemic sites of malignancy. A majority of patients with brain metastases did not have systemic or CNS progression within the first 12 weeks of crizotinib therapy. The main limitations of these data are that 


\begin{tabular}{|c|c|c|c|c|c|c|c|c|c|}
\hline \multirow[b]{2}{*}{ Activity } & \multicolumn{3}{|c|}{$\begin{array}{l}\text { Previously Untreated for BM } \\
\qquad(\mathrm{n}=109)\end{array}$} & \multicolumn{3}{|c|}{$\begin{array}{l}\text { Previously Treated for BM } \\
(\mathrm{n}=166)\end{array}$} & \multicolumn{3}{|c|}{$\begin{array}{l}\text { No BM Detected } \\
(n=613)\end{array}$} \\
\hline & No. of Patients & Outcome & $95 \% \mathrm{Cl}$ & No. of Patients & Outcome & $95 \% \mathrm{Cl}$ & No. of Patients & Outcome & $95 \% \mathrm{Cl}$ \\
\hline \multicolumn{10}{|l|}{ DCR at 12 weeks, $\%$} \\
\hline IC & 109 & 56 & 46 to 66 & 166 & 62 & 54 to 70 & & NA & \\
\hline Systemic & 109 & 63 & 54 to 72 & 166 & 65 & 57 to 72 & 613 & 71 & 68 to 75 \\
\hline \multicolumn{10}{|l|}{ ORR, \% } \\
\hline IC (target lesion BM) & 22 & 18 & 5 to 40 & 18 & 33 & 13 to 59 & & NA & \\
\hline Systemic & 109 & 53 & 43 to 63 & 166 & 46 & 39 to 54 & 613 & 55 & 51 to 59 \\
\hline \multicolumn{10}{|c|}{ Time to tumor response, weeks } \\
\hline IC & 8 & & & 12 & & & & & \\
\hline Median & & 6.0 & & & 6.4 & & & NA & \\
\hline Range* $^{*}$ & & $4.9-12.4$ & & & $5.9-17.7$ & & & NA & \\
\hline Systemic & 58 & & & 77 & & & 336 & & \\
\hline Median & & 6.1 & & & 6.1 & & & 6.1 & \\
\hline Range* $^{*}$ & & $2.0-31.4$ & & & $3.1-35.3$ & & & 3.0-49.1 & \\
\hline \multicolumn{10}{|c|}{ Duration of response, weeks } \\
\hline IC & 8 & & & 12 & & & & & \\
\hline Mediant & & 26.4 & & & NR & & & NA & \\
\hline Range* $^{*}$ & & $6.1-59.3$ & & & $6.0-59.9$ & & & NA & \\
\hline Systemic & 58 & & & 77 & & & 336 & & \\
\hline Mediant & & 47.9 & & & 55.6 & & & 49.0 & \\
\hline Range* & & $5.3-55.0$ & & & $4.4-95.3$ & & & $4.1-96.1$ & \\
\hline \multicolumn{10}{|l|}{ Median PFS, monthst } \\
\hline Overall & 109 & 5.9 & 4.2 to 6.9 & 166 & 6.0 & 4.3 to 9.9 & 613 & 8.8 & 7.9 to 9.9 \\
\hline Systemic & 109 & 8.3 & 6.7 to 14.0 & 166 & 13.5 & 6.2 to 16.5 & 613 & 9.9 & 8.8 to 12.2 \\
\hline \multicolumn{10}{|l|}{ Median TTP, months ${ }^{\prime}$} \\
\hline IC & 109 & 7.0 & 6.7 to 16.4 & 166 & 13.2 & 9.9 to $N R$ & & NA & \\
\hline Systemic & 109 & 12.5 & 7.0 to 14.0 & 166 & 14.0 & 13.5 to 18.0 & & NA & \\
\hline
\end{tabular}

CNS lesions were measured using RECIST, and most of these lesions were identified as nontarget lesions at baseline; in addition, the radiotherapy schemes to palliate brain metastases were not specified or standardized in the PROFILE 1005 and 1007 clinical trials. The late effects of radiotherapy on subsequent intracranial response to TKIs are unknown. Notwithstanding, the presence of confirmed intracranial responses (with measurable decrease in target lesions), as detailed here, can be taken to provide evidence of CNS activity from crizotinib in ALK-rearranged ALK TKI-naive patients. Case reports of CNS responses to crizotinib in crizotinib-naive patients have also been described by others. ${ }^{31}$ However, progression of pre-existing or development of new intracranial lesions while receiving crizotinib therapy was common. Median TTPs were numerically lower for intracranial than for systemic baseline disease. In patients without brain metastases at the time of initiation of crizotinib treatment, $20 \%$ of those who subsequently experienced progression had the CNS as a site of disease

\section{A}

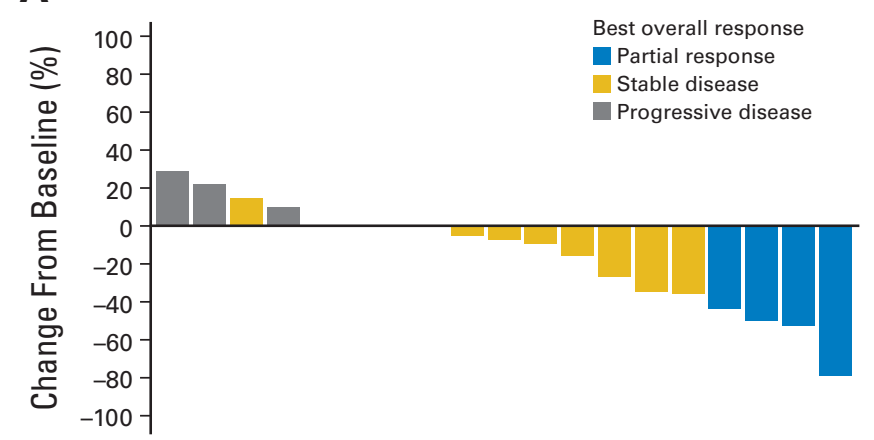

B

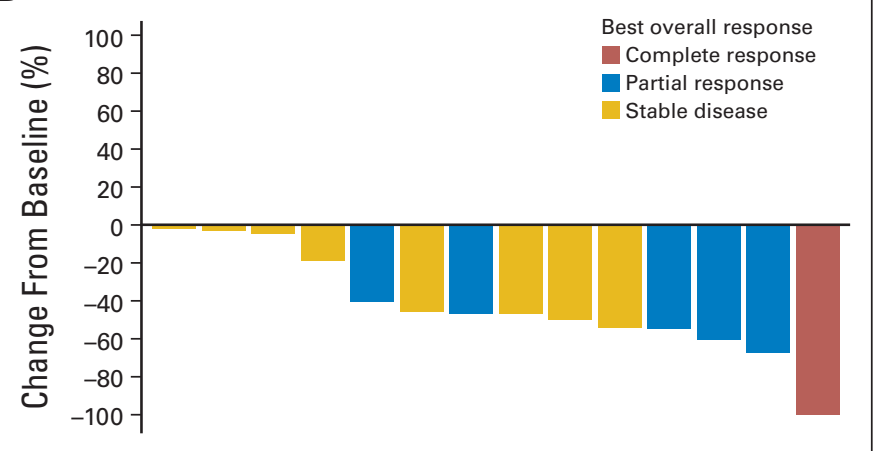

Fig 2. Waterfall plots of best percentage change in intracranial target lesions for patients with $\geq$ one intracranial target lesion at baseline with previously (A) untreated or (B) treated brain metastases. 


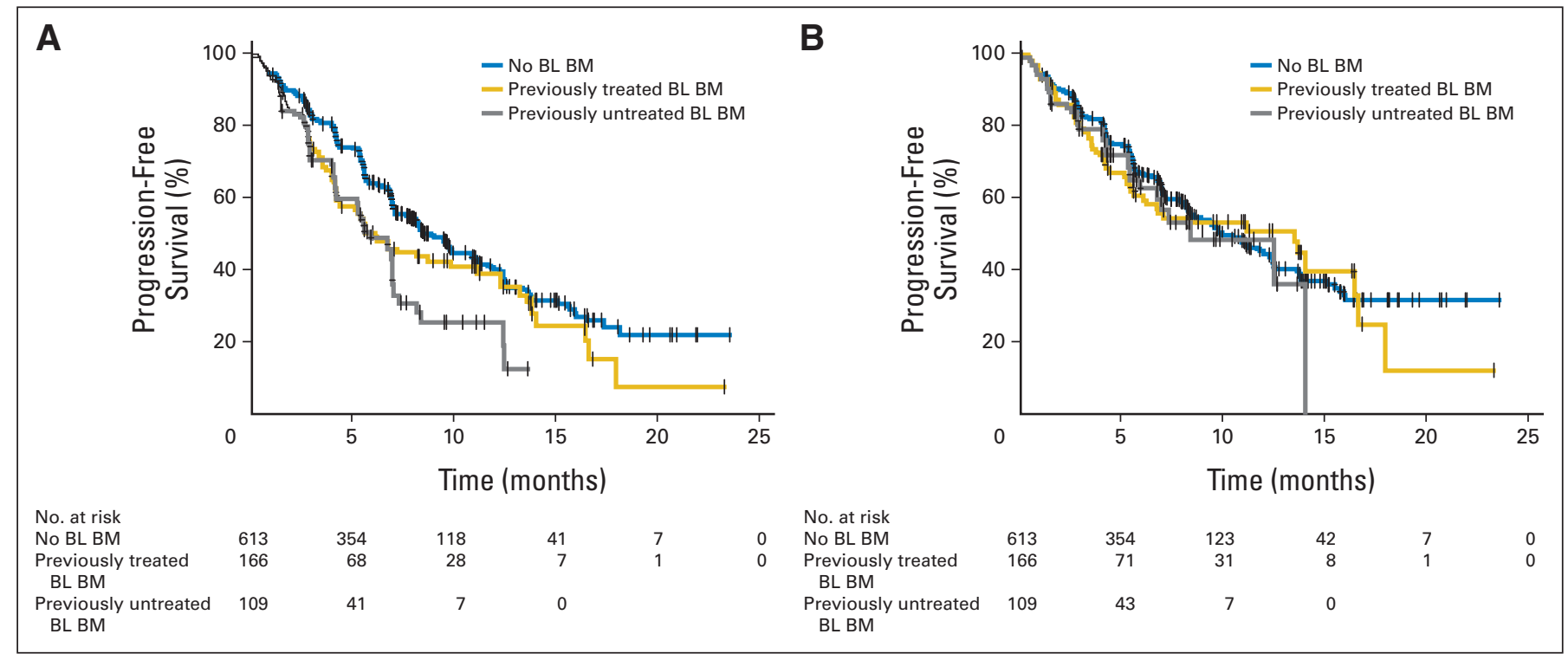

Fig 3. (A) Overall and (B) systemic progression-free survival by treatment group. BL, baseline; BM, brain metastases.

progression. In patients with known brain metastases, the CNS was a site of new lesion or nontarget PD in $70 \%$ of patient cases of PD during crizotinib treatment. These latter numbers are not dissimilar from data available for other oncogene-driven NSCLCs treated with TKIs, such as epidermal growth factor receptor (EGFR) -mutated NSCLC treated with gefitinib or erlotinib. ${ }^{32,33}$ In one report of EGFR-mutated NSCLC, the cumulative incidence of brain metastases in patients without such metastases detected before initiation of EGFR TKI treatment hovered at approximately 15\% after a median of 2 years of follow-up, and progression of previously known brain metastases was almost $50 \%$ after initiation of gefitinib or erlotinib. ${ }^{23,24}$ It is possible that other oncogene-driven lung tumors treated with TKIs will have similar patterns of CNS progression.

Of note, the natural history of $A L K$-rearranged NSCLC within the CNS and its expected rate of progression over time are poorly understood. A direct comparison between how pemetrexed-platinum chemotherapy and crizotinib affect the rate of CNS disease control and the occurrence of the CNS as a primary site of PD is planned for the ongoing first-line PROFILE 1014 randomized trial (ClinicalTrials .gov identifier NCT01154140); this may provide additional insight into how crizotinib may affect the natural history of CNS disease in ALK-rearranged NSCLC. CNS activity has been reported with other multitargeted ALK TKIs, such as ceritinib ${ }^{12,34}$ and alectinib, ${ }^{35,36}$ in patients with $A L K$-rearranged NSCLC who are naive or resistant to crizotinib therapy. Direct comparisons among the ALK TKIs in their systemic and intracranial activities are ongoing. Acquired resistance ${ }^{12}$ to crizotinib and the other ALK TKIs in patients with $A L K$-rearranged NSCLC remains the main limitation in the prolonged palliative benefit of this class of compounds. Acquired resistance to TKI therapy is a common thread among many oncogene-addicted NSCLCs. ${ }^{37}$ In the case of $A L K$-rearranged NSCLC, the major mechanisms of systemic acquired resistance include $A L K$ tyrosine kinase mutations, $A L K$ copy

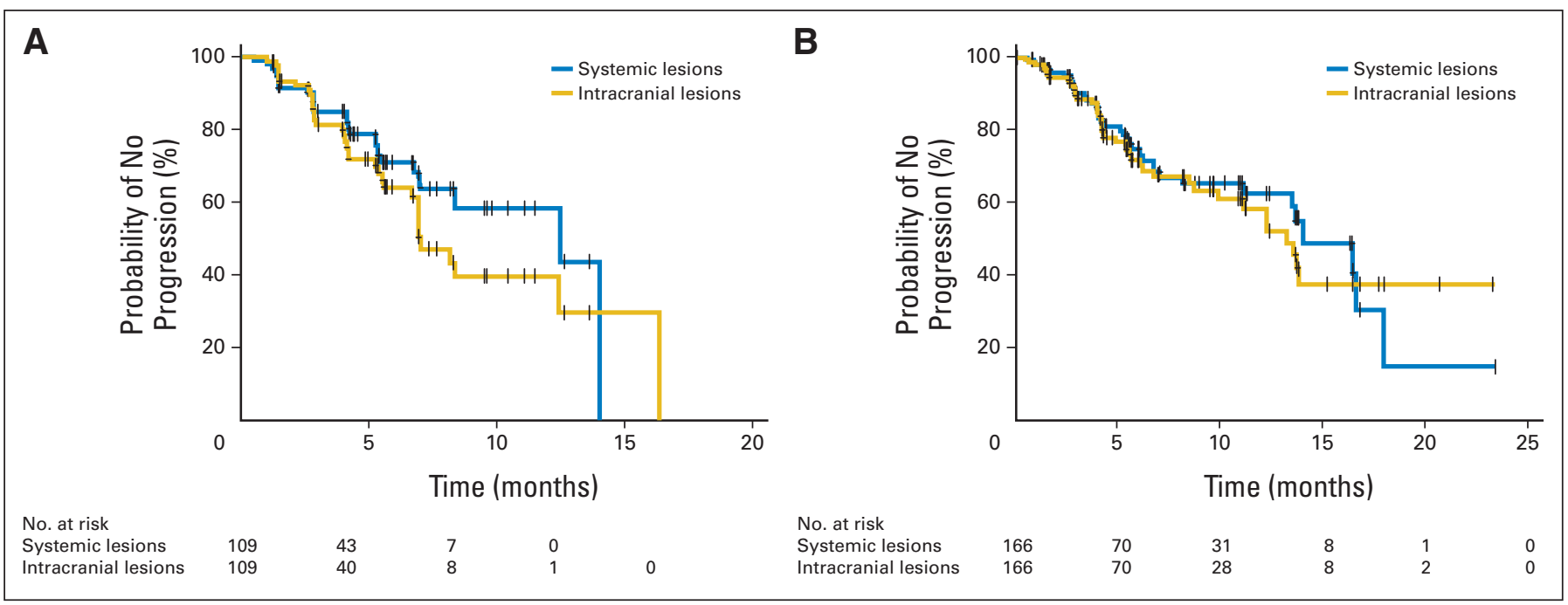

Fig 4. Systemic and intracranial time to progression in patients with previously $(A)$ untreated and $(B)$ treated brain metastases. 
number gains, and oncogene activation of bypass pathways ${ }^{12}$; however, the main mechanisms explaining CNS progression and parenchymal brain concentrations of ALK TKIs are unknown.

The management of isolated sites of progression is not an uncommon clinical presentation among patients treated with crizotinib in the setting of acquired resistance. As reported here, the CNS is often a site of progression. In such cases, many oncologists have instituted policies providing local therapy options (such as whole-brain radiotherapy or stereotactic brain radiotherapy) while continuing crizotinib for systemic disease control, a strategy that seems to provide clinical benefit and prolong the time that crizotinib can provide systemic disease control of nonprogressing lesions. ${ }^{20,22,38}$ Among patients with PD in PROFILE 1001 and 1005, the cohort that continued to receive crizotinib despite RECIST-determined progression (62\% of 194 patients with PD) had significantly longer OS (both from time of $\mathrm{PD}$ and from initial crizotinib treatment) than the group that did not continue crizotinib beyond progression. ${ }^{22}$ Newer strategies to manage CNS progression are eagerly awaited for $A L K$-rearranged NSCLC with intracranial sites of PD. A novel multitargeted ALK and ROS1 TKIPF-06463922 (low-efflux substrate of P-glycoprotein)—was designed to increase potential CNS penetration and to act as a more potent ALK TKI than crizotinib. ${ }^{39}$ A phase I clinical trial of PF-06463922 (ClinicalTrials.gov identifier NCT01970865) is under way and may demonstrate whether this drug can be effective in treating patients with $A L K$-rearranged NSCLC with CNS disease in the crizotinibnaive or -resistant setting.

In summary, we report, to our knowledge, the largest cohort of patients with $A L K$-rearranged NSCLC with brain metastases. Crizotinib was associated with more than $55 \%$ disease control within the CNS at 12 weeks of therapy, comparable to the rate observed system- ically. Crizotinib was also associated with a moderate (18\% to $33 \%$ ) but RECIST-confirmed CNS ORR among patients with measurable brain metastases before initiation of this TKI. However, the CNS remains one of the dominant sites of progressive tumor burden during crizotinib therapy. Further research into mechanisms of acquired progression within the CNS during therapy with crizotinib and other ALK TKIs will help define the use of these agents in this setting.

\section{AUTHORS' DISCLOSURES OF POTENTIAL CONFLICTS} OF INTEREST

Disclosures provided by the authors are available with this article at www.jco.org.

\section{AUTHOR CONTRIBUTIONS}

Conception and design: Daniel B. Costa, Alice T. Shaw, Robin Wiltshire, D. Ross Camidge, Lucio Crinò

Financial support: Daniel B. Costa

Administrative support: Keith D. Wilner, Robin Wiltshire

Provision of study materials or patients: Daniel B. Costa, Alice T. Shaw, Sai-Hong I. Ou, Benjamin J. Solomon, Gregory J. Riely, Myung-Ju Ahn, Caicun Zhou

Collection and assembly of data: Daniel B. Costa, Alice T. Shaw, Paulina Selaru, Anna Polli

Data analysis and interpretation: Daniel B. Costa, Alice T. Shaw, Sai-Hong I. Ou, Benjamin J. Solomon, Gregory J. Riely, Myung-Ju Ahn, Caicun Zhou, S. Martin Shreeve, Anna Polli, Patrick Schnell, Keith D. Wilner, Robin Wiltshire, D. Ross Camidge, Lucio Crinò

Manuscript writing: All authors Final approval of manuscript: All authors

\section{REFERENCES}

1. Jemal A, Bray F, Center MM, et al: Global cancer statistics. CA Cancer J Clin 61:69-90, 2011

2. Garraway LA, Verweij J, Ballman KV: Precision oncology: An overview. J Clin Oncol 31:18031805, 2013

3. Cheng $L$, Alexander RE, Maclennan GT, et al: Molecular pathology of lung cancer: Key to personalized medicine. Mod Pathol 25:347-369, 2012

4. Soda $M$, Choi $Y L$, Enomoto $M$, et al: Identification of the transforming EML4-ALK fusion gene in non-small-cell lung cancer. Nature 448:561-566, 2007

5. Ou SH, Bartlett $\mathrm{CH}$, Mino-Kenudson $\mathrm{M}$, et al: Crizotinib for the treatment of ALK-rearranged nonsmall cell lung cancer: A success story to usher in the second decade of molecular targeted therapy in oncology. Oncologist 17:1351-1375, 2012

6. Choi YL, Takeuchi K, Soda M, et al: Identification of novel isoforms of the EML4-ALK transforming gene in non-small cell lung cancer. Cancer Res 68:4971-4976, 2008

7. Inamura $K$, Takeuchi $K$, Togashi $Y$, et al: EML4-ALK fusion is linked to histological characteristics in a subset of lung cancers. J Thorac Oncol 3:13-17, 2008

8. Rodig SJ, Mino-Kenudson M, Dacic S, et al: Unique clinicopathologic features characterize ALKrearranged lung adenocarcinoma in the Western population. Clin Cancer Res 15:5216-5223, 2009

9. Koivunen JP, Mermel C, Zejnullahu $K$, et al: EML4-ALK fusion gene and efficacy of an ALK kinase inhibitor in lung cancer. Clin Cancer Res 14:4275-4283, 2008

10. Shaw AT, Yeap BY, Mino-Kenudson M, et al: Clinical features and outcome of patients with nonsmall-cell lung cancer who harbor EML4-ALK. J Clin Oncol 27:4247-4253, 2009

11. Inamura $K$, Takeuchi $K$, Togashi $Y$, et al: EML4-ALK lung cancers are characterized by rare other mutations, a TTF-1 cell lineage, an acinar histology, and young onset. Mod Pathol 22:508-515, 2009

12. Shaw AT, Engelman JA: ALK in lung cancer: Past, present, and future. J Clin Oncol 31:11051111, 2013

13. Christensen JG, Zou HY, Arango ME, et al: Cytoreductive antitumor activity of PF-2341066, a novel inhibitor of anaplastic lymphoma kinase and c-Met, in experimental models of anaplastic largecell lymphoma. Mol Cancer Ther 6:3314-3322, 2007

14. Settleman J: Cell culture modeling of genotypedirected sensitivity to selective kinase inhibitors: Targeting the anaplastic lymphoma kinase (ALK). Semin Oncol 36:S36-S41, 2009

15. McDermott U, lafrate AJ, Gray NS, et al: Genomic alterations of anaplastic lymphoma kinase may sensitize tumors to anaplastic lymphoma kinase inhibitors. Cancer Res 68:3389-3395, 2008

16. Yasuda H, Figueiredo-Pontes LL, Kobayashi S, et al: Preclinical rationale for use of the clinically available multitargeted tyrosine kinase inhibitor crizotinib in ROS1-translocated lung cancer. J Thorac Oncol 7:1086-1090, 2012
17. Bergethon K, Shaw AT, Ou SI, et al: ROS1 rearrangements define a unique molecular class of lung cancers. J Clin Oncol 30:863-870, 2012

18. Kwak EL, Bang YJ, Camidge DR, et al: Anaplastic lymphoma kinase inhibition in non-small-cell lung cancer. N Engl J Med 363:1693-1703, 2010

19. Camidge DR, Bang YJ, Kwak EL, et al: Activity and safety of crizotinib in patients with ALK-positive non-small-cell lung cancer: Updated results from a phase 1 study. Lancet Oncol 13:1011-1019, 2012

20. Camidge DR, Doebele RC: Treating ALKpositive lung cancer: Early successes and future challenges. Nat Rev Clin Oncol 9:268-277, 2012

21. Shaw AT, Kim DW, Nakagawa K, et al: Crizotinib versus chemotherapy in advanced ALK-positive lung cancer. N Engl J Med 368:2385-2394, 2013

22. Ou SH, Jänne PA, Bartlett $\mathrm{CH}$, et al: Clinical benefit of continuing ALK inhibition with crizotinib beyond initial disease progression in patients with advanced ALK-positive NSCLC. Ann Oncol 25:415422, 2014

23. Heon S, Yeap BY, Britt GJ, et al: Development of central nervous system metastases in patients with advanced non-small cell lung cancer and somatic EGFR mutations treated with gefitinib or erlotinib. Clin Cancer Res 16:5873-5882, 2010

24. Heon S, Yeap BY, Lindeman NI, et al: The impact of initial gefitinib or erlotinib versus chemotherapy on central nervous system progression in advanced non-small cell lung cancer with EGFR mutations. Clin Cancer Res 18:4406-4414, 2012

25. Motl S, Zhuang Y, Waters CM, et al: Pharmacokinetic considerations in the treatment of CNS tumours. Clin Pharmacokinet 45:871-903, 2006 
26. Clarke JL, Pao W, Wu N, et al: High dose weekly erlotinib achieves therapeutic concentrations in CSF and is effective in leptomeningeal metastases from epidermal growth factor receptor mutant lung cancer. J Neurooncol 99:283-286, 2010

27. Jackman DM, Holmes AJ, Lindeman $\mathrm{N}$, et al: Response and resistance in a non-small-cell lung cancer patient with an epidermal growth factor receptor mutation and leptomeningeal metastases treated with high-dose gefitinib. J Clin Oncol 24: 4517-4520, 2006

28. Eisenhauer EA, Therasse $P$, Bogaerts J, et al: New Response Evaluation Criteria in Solid Tumours: Revised RECIST guideline (version 1.1). Eur J Cancer 45:228-247, 2009

29. Awad MM, Shaw AT: ALK inhibitors in nonsmall cell lung cancer: Crizotinib and beyond. Clin Adv Hematol Oncol 12:429-439, 2014

30. Costa DB, Kobayashi S, Pandya SS, et al: CSF concentration of the anaplastic lymphoma kinase inhibitor crizotinib. J Clin Oncol 29:e443-e445, 2011
31. Camidge DR: Taking aim at ALK across the blood-brain barrier. J Thorac Oncol 8:389-390, 2013

32. Maemondo $M$, Inoue $A$, Kobayashi $K$, et al: Gefitinib or chemotherapy for non-small-cell lung cancer with mutated EGFR. N Engl J Med 362:23802388, 2010

33. Rosell R, Carcereny E, Gervais R, et al: Erlotinib versus standard chemotherapy as first-line treatment for European patients with advanced EGFR mutation-positive non-small-cell lung cancer (EURTAC): A multicentre, open-label, randomised phase 3 trial. Lancet Oncol 13:239-246, 2012

34. Shaw AT, Kim DW, Mehra R, et al: Ceritinib in ALK-rearranged non-small-cell lung cancer. N Engl J Med 370:1189-1197, 2014

35. Seto T, Kiura K, Nishio M, et al: $\mathrm{CH} 5424802$ (RO5424802) for patients with ALK-rearranged advanced non-small-cell lung cancer (AF-001JP study): A single-arm, open-label, phase 1-2 study. Lancet Oncol 14:590-598, 2013

36. Gadgeel SM, Gandhi L, Riely GJ, et al: Safety and activity of alectinib against systemic disease and brain metastases in patients with crizotinibresistant ALK-rearranged non-small-cell lung cancer (AF-002JG): Results from the dose-finding portion of a phase 1/2 study. Lancet Oncol 15:1119-1128, 2014

37. Ohashi K, Maruvka YE, Michor F, et al: Epidermal growth factor receptor tyrosine kinase inhibitor-resistant disease. J Clin Oncol 31:1070-1080, 2013

38. Weickhardt AJ, Scheier B, Burke JM, et al: Local ablative therapy of oligoprogressive disease prolongs disease control by tyrosine kinase inhibitors in oncogene-addicted non-small-cell lung cancer. J Thorac Oncol 7:1807-1814, 2012

39. Johnson TW, Bailey S, Burke BJ, et al: Is CNS availability for oncology a no-brainer? Discovery of PF-06463922, a novel small molecule inhibitor of ALK/ROS1 with preclinical brain availability and broad spectrum potency against ALK-resistant mutations. Mol Cancer Ther 12, 2013 (suppl; abstr PR10)

\section{Support}

Supported by Pfizer and in part by Grants No. CA090578, CA058187, and CA164273 from the National Cancer Institute, by the American Society of Clinical Oncology Conquer Cancer Foundation, and by Grant No. RSG 11-186 from the American Cancer Society.

\section{GLOSSARY TERMS}

anaplastic lymphoma kinase (ALK): an enzyme that, in humans, is encoded by the $A L K$ gene.

non-small-cell lung cancer (NSCLC): a type of lung cancer that includes squamous cell carcinoma, adenocarcinoma, and large-cell carcinoma. tyrosine kinase inhibitors: molecules that inhibit the activity of tyrosine kinase receptors. Tyrosine kinase inhibitors are small molecules developed to inhibit the binding of ATP to the cytoplasmic region of the receptor (eg, gefitinib), thus further blocking the cascade of reactions that is activated by the pathway. 


\section{AUTHORS' DISCLOSURES OF POTENTIAL CONFLICTS OF INTEREST}

\section{Clinical Experience With Crizotinib in Patients With Advanced ALK-Rearranged Non-Small-Cell Lung Cancer and Brain Metastases}

The following represents disclosure information provided by authors of this manuscript. All relationships are considered compensated. Relationships are self-held unless noted. I = Immediate Family Member, Inst = My Institution. Relationships may not relate to the subject matter of this manuscript. For more information about ASCO's conflict of interest policy, please refer to www.asco.org/rwc or jco.ascopubs.org/site/ifc.

\section{Daniel B. Costa}

Honoraria: Pfizer

Consulting or Advisory Role: Pfizer, Roche, AstraZeneca

\section{Alice T. Shaw}

Honoraria: Pfizer, Novartis, Roche

Consulting or Advisory Role: Pfizer, Novartis, Genentech, Chugai Pharmaceutical, ARIAD Pharmaceuticals, Ignyta, Daiichi Sankyo Research Funding: Pfizer (Inst), Novartis (Inst), ARIAD

Pharmaceuticals (Inst), Ignyta (Inst), Bristol-Myers Squibb (Inst), Genentech (Inst)

\section{Sai-Hong I. Ou}

Consulting or Advisory Role: Pfizer, Roche/Genentech Speakers' Bureau: Roche/Genentech, Pfizer, Celgene, Boehringer Ingelheim

Research Funding: Pfizer (Inst), Roche/Genentech (Inst), AstraZeneca/ MedImmune (Inst), Astellas Pharma (Inst), Clovis Oncology (Inst)

Benjamin J. Solomon

Consulting or Advisory Role: Pfizer

Gregory J. Riely

Consulting or Advisory Role: Mersana, Novartis, ARIAD

Pharmaceuticals

Research Funding: Novartis (Inst), Roche/Genentech (Inst), Millennium Pharmaceuticals (Inst), GlaxoSmithKline (Inst), Pfizer (Inst), Infinity (Inst)

\section{Myung-Ju Ahn}

No relationship to disclose

\section{Caicun Zhou}

No relationship to disclose

\section{S. Martin Shreeve}

Employment: Janssen Pharmaceuticals

Stock or Other Ownership: Pfizer, Johnson \& Johnson

Paulina Selaru

Employment: Pfizer

Stock or Other Ownership: Pfizer, Zoetis, EnteroMedics (I), Nxstage Medical (I)

\section{Anna Polli}

Employment: Pfizer

Stock or Other Ownership: Pfizer

Patrick Schnell

Employment: Pfizer

Stock or Other Ownership: Pfizer

Keith D. Wilner

Employment: Pfizer

Stock or Other Ownership: Pfizer

Robin Wiltshire

Employment: Pfizer

Stock or Other Ownership: Pfizer

D. Ross Camidge

No relationship to disclose

\section{Lucio Crinò}

Honoraria: Pfizer, AstraZeneca, Boehringer Ingelheim

Travel, Accommodations, Expenses: Pfizer, AstraZeneca, Boehringer Ingelheim 


\section{Acknowledgment}

We thank all of the participating patients and their families, as well as the network of investigators, research nurses, study coordinators, and operations staff for PROFILE 1005 and 1007. The trials were sponsored by Pfizer. Editorial assistance was provided by Wendy Sacks at ACUMED (Tytherington, United Kingdom) and was funded by Pfizer.

The sponsor of the study participated in the study design, collection, analysis, and interpretation of data. The report was written with contributions and review by all authors. The authors had full access to all data and had final responsibility for the decision to submit the report for publication.

\section{Appendix}

\section{Crizotinib and Clinical Trials}

Crizotinib has been evaluated in ALK-rearranged non-small-cell lung cancer (NSCLC) in the following clinical studies: the expansion cohort of a phase I trial (PROFILE 1001; ClinicalTrials.gov identifier NCT00585195), a phase II trial (PROFILE 1005; ClinicalTrials.gov identifier NCT00932451), and two worldwide phase III trials (PROFILE 1007; ClinicalTrials.gov identifier NCT00932893 [crizotinib $v$ chemotherapy in second-line setting] and PROFILE 1014; ClinicalTrials.gov identifier NCT01154140 [crizotinib $v$ chemotherapy in first-line setting]). In the initial 149 patients with ALK-rearranged NSCLC from the PROFILE 1001 trial, crizotinib led to a response rate (RR) of $60.8 \%$ (95\% CI, 52.3 to 68.9), with a median progression-free survival (PFS) of 9.7 months ( $95 \%$ CI, 7.7 to 12.8 ) and an estimated overall survival (OS) of $74.8 \%$ (95\% CI, 66.4 to 81.5$)$ at 12 months. ${ }^{18,19}$ The results of PROFILE 1005 have not been published. In PROFILE 1007, crizotinib was associated with an RR of 65\% (95\% CI, 58 to 72), as compared with an RR of $20 \%$ ( $95 \%$ CI, 14 to 26) with chemotherapy (docetaxel or pemetrexed); the median PFS also was improved with crizotinib to 7.7 months, as compared with 3.0 months in the chemotherapy group (hazard ratio for progression or death with crizotinib, $0.49 ; 95 \%$ CI, 0.37 to 0.64 ; $P<.001$ ); the median OS was 20.3 months ( $95 \%$ CI, 18.1 to not reached) with crizotinib and 22.8 months (95\% CI, 18.6 to not reached) with chemotherapy (hazard ratio for death in crizotinib group, 1.02; 95\% CI, 0.68 to $1.54 ; P=.54$ ). ${ }^{21}$

\section{Patients and Treatment}

Key differences between PROFILE 1005 and 1007 were that patients enrolled onto PROFILE 1007 could only have had one prior chemotherapy regimen that had to have been platinum based, whereas those in PROFILE 1005 could have had more than one prior regimen, with non-platinum-based regimens allowed.

\section{Measurements of Systemic Disease and Brain Sites of Disease}

Per RECIST (version 1.1), lesions situated in previously irradiated areas are not considered measurable unless they demonstrate progression after irradiation. The late effects of prior radiotherapy on measurements of lesions using RECIST (version 1.1) are unknown for ALK-rearranged NSCLC. Target lesions (which generally include all measurable lesions representative of all involved organs) were measured at baseline and at each stipulated imaging assessment. All other lesions, considered nontarget lesions, were observed at baseline and on treatment but were assessed only qualitatively to be present, absent, or increased (represented unequivocal progression). In contrast to RECIST categories defined for target lesions (complete response, partial response, stable disease, and progressive disease [PD]), response in nontarget lesions was defined only as complete response (disappearance of all nontarget lesions), stable disease (persistence of $\geq$ one nontarget lesion), and PD (unequivocal progression of existing nontarget lesions or appearance of $\geq$ one new lesion). In the absence of standard minimum tumor growth criteria defining individual sites of PD when there were multiple sites of progressing target lesions, we analyzed the subset of patients who had PD involving new lesions and/or nontarget lesions.

\section{Statistical Analyses}

The 6-month survival probability was estimated using the Kaplan-Meier method, and a two-sided $95 \%$ CI for the $\log [-\log (6-$ month survival probability)] was calculated using a normal approximation and then back transformed to give a CI for the 6-months survival probability itself. The 1-year survival probability was estimated similarly.

Overall PFS was defined as the time from the first dose (PROFILE 1005) or from random assignment (PROFILE 1007) to the first documentation of objective tumor progression or death resulting from any cause (whichever occurred first). Systemic PFS was defined similar to overall PFS, but only sites of systemic (extracranial) disease were evaluated for tumor progression. OS was defined as the time from the first dose (PROFILE 1005) or from random assignment (PROFILE 1007) to the date of death resulting from any cause. Duration of follow-up for overall PFS was calculated based on the reverse Kaplan-Meier method. The median duration of follow-up for overall PFS for patients with untreated brain metastases was 5.9 months, for patients with previously treated brain metastases, 8.2 months, and for patients without brain metastases, 9.5 months. 